\title{
One plus one: Two free flaps from same donor thigh for simultaneous coverage of two different defects
}

\author{
Susmitha Bandi, Rayidi Venkata Koteswara Rao, Damalacheruvu Mukunda Reddy ${ }^{1}$ \\ Department of Plastic Surgery, Nizam's Institute of Medical Sciences, 'Indo American Cancer Center, Hyderabad, Telangana, \\ India
}

Address for correspondence: Dr. Susmitha Bandi, C/O Sri P. Raja Ernest Reddy, 10-2-1/A, Dwarka Pershad Nivas, Opp Geetha nursing home, Marredpally, Secunderabad. 500026, Telangana, India. E-mail: susmithabandi@gmail.com

\section{ABSTRACT}

Introduction: Primary microvascular reconstruction of multiple defects is challenging particularly if it has to be simultaneous. In trauma cases, harvesting two independent free flaps from different sites is very time-consuming and adds to morbidity. To eliminate these disadvantages, we sought to find out a reliable alternative method of harvesting two independent free flaps based on the descending branch of circumflex femoral artery, i.e., one anterolateral thigh (ALT) flap and one rectus femoris muscle flap. Aim: To study the feasibility of transferring two free flaps, i.e., ALT and rectus femoris muscle flap simultaneously from the same thigh for coverage of two different limb defects. Materials and Methods: From 2003 to 2012, five patients with two defects each were managed with a total of ten flaps harvested from five donor sites based on independent pedicles of descending branch of lateral circumflex femoral artery and used to cover severe injuries of extremities. Three cases had both lower limb defects and two cases had one upper limb and one lower limb defect. In each case, one ALT flap and one rectus femoris muscle flap were used for coverage. Results: All reconstructive procedures were completed without any major complications. All flaps survived well. There were no re-explorations and no complications related to donor sites. Conclusion: We conclude that our approach of simultaneous harvest of ALT and rectus femoris muscle from the same thigh offers two flaps for two different defects in terms of economy of donor site and operating time.

\section{KEY WORDS}

Composite tissue transfer; multiple flaps; multiple limb defects; single donor site

\section{INTRODUCTION}

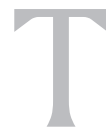

he perforator-based flaps such as the anterolateral thigh (ALT) flap have superseded the use of musculocutaneous and muscle flaps

\begin{tabular}{|l|l|}
\hline \multicolumn{2}{|c|}{ Access this article online } \\
\hline Quick Response Code: & Website: \\
\hline & www.ijps.org \\
\hline & \\
\hline
\end{tabular}

for the reconstruction of acquired soft tissue defects in the limbs. ${ }^{[1]}$ It has many advantages including large skin territory, long pedicle and minimal donor site morbidity. ${ }^{[2,3]}$

This is an open access article distributed under the terms of the Creative Commons Attribution-NonCommercial-ShareAlike 3.0 License, which allows others to remix, tweak, and build upon the work non-commercially, as long as the author is credited and the new creations are licensed under the identical terms.

For reprints contact: reprints@medknow.com

How to cite this article: Bandi S, Koteswara Rao RV, Reddy DM. One plus one: Two free flaps from same donor thigh for simultaneous coverage of two different defects. Indian J Plast Surg 2016;49:191-7. 
The rectus femoris is a long thick fusiform muscle that originates from anterior superior iliac spine and upper part of acetabulum. The dominant blood supply is from descending branch of lateral circumflex femoral artery; it is a Type II muscle as per Mathes and Nahai classification. It is innervated by a branch of femoral nerve and acts to extend the knee and flex the thigh. Although it has been described initially as a pedicled flap, ${ }^{[4]}$ it has been used as a free muscle flap or myocutaneous flap also, ${ }^{[5]}$ both for coverage of defects and for free functioning muscle transfer. ${ }^{[6,7]}$ Its advantages include single dominant neurovascular pedicle, long motor nerve and a large reliable overlying skin paddle. ${ }^{[8]}$

The blood supply of both ALT and rectus femoris arise from the same vascular system, i.e., the descending branch of lateral circumflex femoral artery. This arterial system has served as the basis for many composite and chimeric flaps to fulfil varying reconstructive needs. ${ }^{[9]}$ Units that deal with a large quantum of limb trauma may often be called to deal with coverage issues of two separate limb defects in the emergency situation; harvesting two different flaps from two separate donor sites has been described but often is time-consuming and may prevent a single stage reconstruction for logistic reasons. ${ }^{[10]}$ Two flaps have been harvested from amputated limbs and used for coverage of defects. ${ }^{[1]]}$ The purpose of this paper is to present the clinical results of transferring ALT flap and rectus femoris muscle flap simultaneously from the same thigh for coverage of two different limb defects.

\section{Aims}

To study the feasibility of transferring two free flaps, i.e., ALT and rectus femoris muscle flap simultaneously from the same thigh for coverage of two different limb defects.

\section{Objectives}

1. To note the major motor nerve to the vastus lateralis muscle and its relation to safe flap harvest

2. To note the amount of area that could be covered by the rectus femoris muscle flap

3. To note the complications of the procedure.

\section{MATERIALS AND METHODS}

Five patients were reconstructed with double free flaps, i.e., one ALT and one rectus femoris muscle flap harvested from the same thigh for two different defects each. Four patients were victims of road traffic accidents, and one got injured in a train accident. There were three males and two females aged between 20 and 50 years. All of them had two soft tissue defects [Figures 1a-c, 2a and $3 a$ ] each requiring free tissue transfer. Three of them had bilateral lower limb defects [Figures 2a and 3a], and two of them had one upper and one lower limb defect [Figure 1a-c]. After debridement, the fractures were fixed by the orthosurgeons. Rectus femoris muscle flap cover with split skin grafting was done for the smaller defect and ALT flap was used for larger of the defects. The size and orientation of ALT flap was planned according to the defect. The demographic details of the patients are shown in Table 1.

\section{Surgical technique}

Pre-operative planning of ALT flap perforator location was done with hand held Doppler. Infiltration of adrenaline solution of strength 1 in 200,000 was given along the line of incision. The incision for exploration of ALT perforator is given; flap elevation was started by a subfascial medial incision corresponding to the lateral border of the rectus femoris muscle. A suitable perforator was identified and noted whether musculocutaneous or septocutaneous. The perforator was dissected proximally up to descending

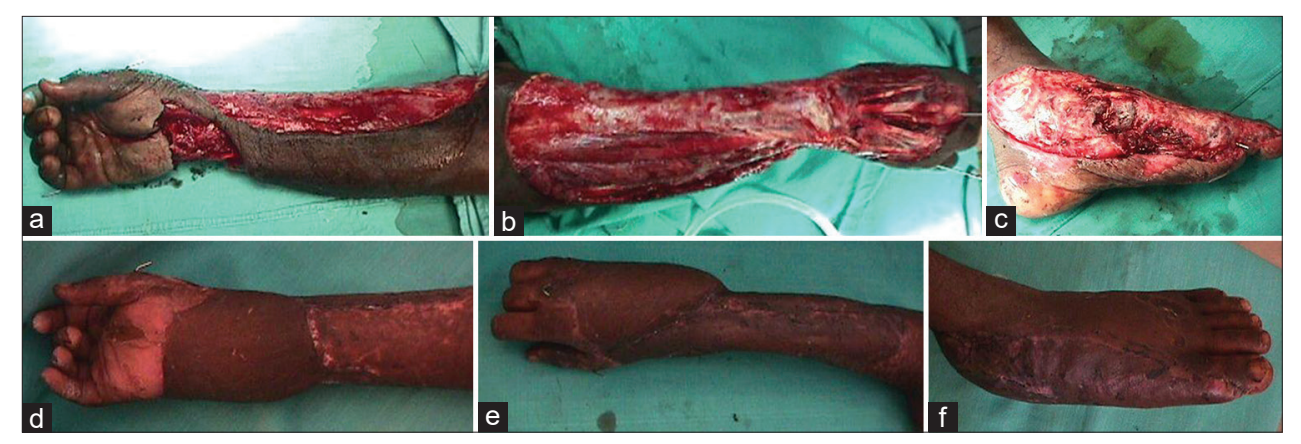

Figure 1: (a) Patient 1, right forearm and wrist avulsion injury, (b) Right dorsal forearm defect, (c) Left foot crush injury, (d) Right forearm and wrist covered with anterolateral thigh flap, (e) Right dorsal forearm defect covered with same anterolateral thigh flap, (f) Left foot covered with rectus femoris flap immediate post-operative figure, showing good contour 
branch of lateral circumflex femoral artery to lead to the dominant pedicle of the rectus femoris muscle; the minor
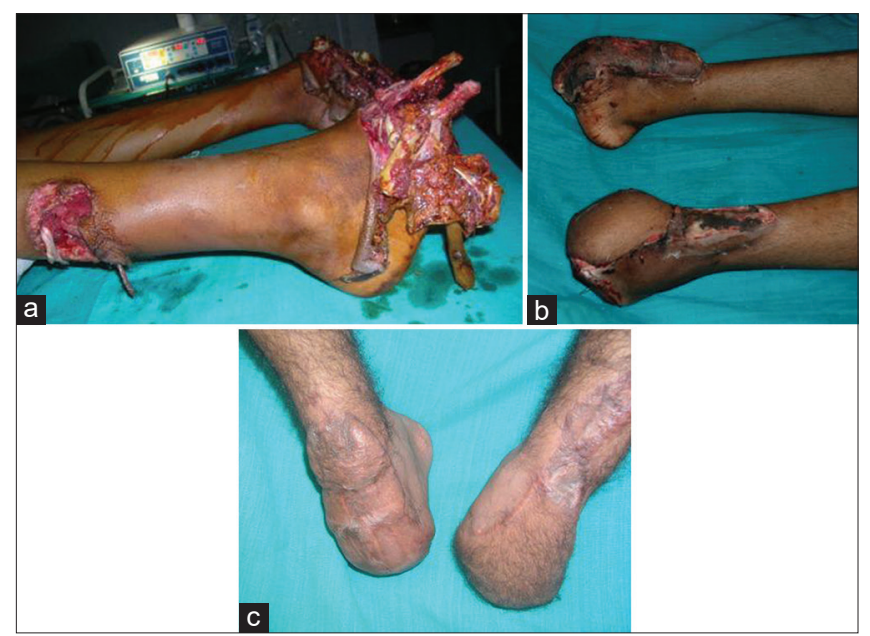

Figure 2: (a) Patient 3, crush injury both feet with mid tarsal amputation and loss of skin till hind foot, (b) Immediate post-operative result right rectus, left anterolateral thigh, (c) 2 years post-operative after both flaps thinning, giving good contour pedicles to the rectusfemoriswere clipped. The area around the common pedicle was defined to identify the pattern of vascular supply (whether there were independent veins or a common vein for both flaps). Initial part of the pedicle dissection for the rectus femoris dominant pedicle was done by retracting rectus femoris laterally and then the common pedicle was dissected by retracting the muscle medially. The course of nerve to vastus lateralis was noted in relation to the pedicle. Proximal to the dominant pedicle of the rectus femoris its motor nerve/nerves were dissected to enable their division and any other minor vascular pedicles entering proximal to the main pedicle were clipped. The skin needs were transposed to the thigh to circumscribe the ALT flap; ALT flap was raised preserving fascia and iliotibial tract on the lateral aspect of thigh; while dissecting the pedicle, the nerve to vastus lateralis muscle was preserved in all the cases. Perfusion of the flaps was checked and detachment done after Confirmation of vessels flows at the recipient site. Ex vivo
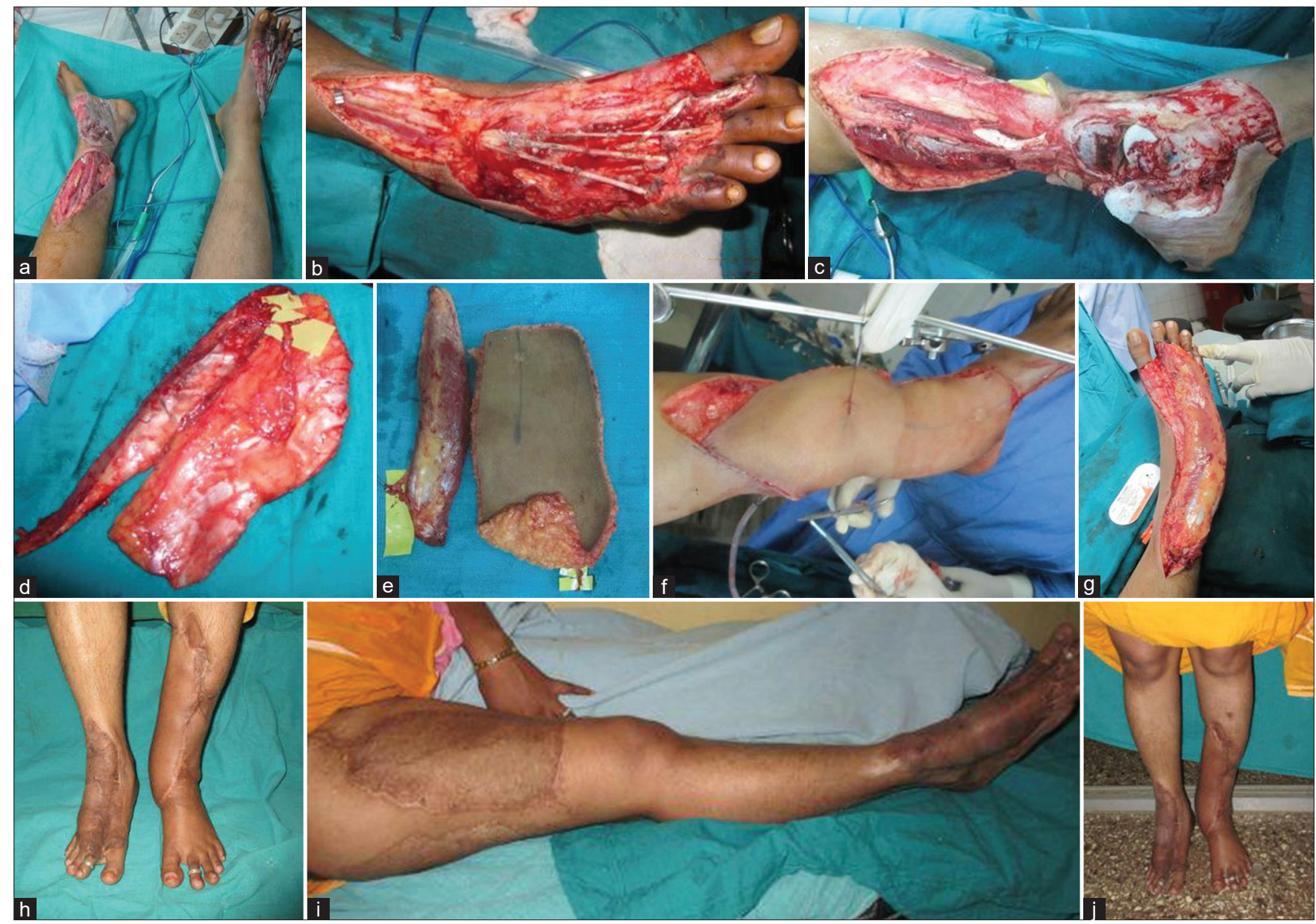

Figure 3: (a) Post-traumatic both lower limb defects requiring flap cover in case 5 of Table 1, (b) Right foot with exposed tendons after debridement, (c) Left leg middle third fracture and exposed ankle joint, medial foot after debridement, (d) Anterolateral thigh and rectus after detachment from thigh and before separation,

(e) Anterolateral thigh and rectus after separation, (f) Completed inset of ALTover leg and ankle, (g) Completed inset of rectus over entire foot dorsum, (h) Two years post-operative follow-up photograph showing settled flaps, (i) Donor right thigh the grafted area and no extensor lag at knee, (j) Two years follow-up photograph with patient standing 
the flaps [Figure 3d] were divided into two flaps [Figure 3e] under loupe magnification before being transferred to the recipient defects. In one case, the major motor branch to the vastus lateralis was going in between the pedicles of ALT and Rectus Femoris; hence to preserve this branch, the flaps hadto be divided in vivo. In all cases ALT pedicles was divided just at its origin from the common pedicles and the common pedicle was included along with rectus pedicles [Figure 4] to increase its length. Microvascular anastomosis was performed simultaneously using 8-0 or 9-0 monofilament nylon for one artery and one vein using operating microscope for the smaller vessels and 4X loupe for the larger vessels. The distal stump of the rectus femoris tendon was reefed to the vastus lateralis and quadriceps tendon with 3-0 polyglecaprone sutures holding the knee in neutral position.

\section{Review of literature}

The ALT flap was first reported by Song et al. in 1984..$^{[1]}$ The rectus femoris has been used as a pedicled flap for lower abdominal reconstruction ${ }^{[5,6]}$ this muscle has got a reliable vascular supply. The dominant vascular pedicle enters the deep medial aspect of the muscle belly approximately $8-10 \mathrm{~cm}$ below the anterior inferior iliac spine. Retraction of the sartorius muscle medially and the rectus femoris muscle laterally in the proximal third of the leg allows identification of its dominant vascular pedicle, from the descending branch of the lateral circumflex femoral artery. ${ }^{[8]}$ Tamai et al. described the first successful microvascular transfer of rectus femoris muscle flap in dogs. ${ }^{[12]}$ Schenck in 1977 did a free functional rectus femoris muscle transfer (FFMT) for repair of traumatic loss of all forearm flexors. ${ }^{[13]}$ Koshima et al. used as FFMT in facial paralysis. ${ }^{[7]}$

Harvesting more than one flap for the management of complex defects has been described in the past. Certain areas the body were identified, notably the long subscapular thoracodorsal pedicle and lateral circumflex femoral system with multiple side branches and tissue components. The scapular system of vessels has permitted the use of multiple flaps-latissimus dorsi, serratus anterior and the parascapular flap as chimeric or multiple flaps to manage complex defects. ${ }^{[14]}$ From the branches of lateral circumflex femoral system, flaps such as ALT, vastus lateralis, tensor fascia lata and rectus femoris can be harvested in various combinations. ${ }^{[15]}$ Lin et al. over a 6-year period reported 44 composite flaps which had been harvested to reconstruct skin and musculotendinous defects using the ALT, vastus lateralis and rectus femoris flaps with a success rate of $97.7 \%{ }^{.15]}$

Table 1: Demographic details and injury details of patients

\begin{tabular}{|c|c|c|c|c|c|c|}
\hline Serial & Age & Sex & Mode of injury & Limbs affected & Injury details & Other injuries \\
\hline 1 & 20 & Male & $\mathrm{RTA}^{*}$ & UL and LL & $\begin{array}{l}\text { Right forearm avulsion [Figure 1a and b], left foot medial } \\
\text { skin loss [Figure 1c] }\end{array}$ & None \\
\hline 2 & 50 & Male & RTA & LL and LL & $\begin{array}{l}\text { Left heel sole avulsion and right lower third fracture leg } \\
\text { Grade IIIB' }\end{array}$ & None \\
\hline 3 & 22 & Male & Train accident & $\mathrm{LL}$ and $\mathrm{LL}$ & Bilateral crush injury foot [Figure 2a] & $\begin{array}{l}\text { Nonreplantable, bilateral } \\
\text { hand amputation }\end{array}$ \\
\hline 4 & 50 & Female & RTA & UL and LL & Avulsion left hand dorsum and left foot medially & None \\
\hline 5 & 30 & Female & RTA & LL and LL & $\begin{array}{l}\text { Avulsion right foot dorsum [Figure 3b] and middle third } \\
\text { fracture left leg Grade IIIB crush ankle and foot [Figure 3c] }\end{array}$ & None \\
\hline
\end{tabular}

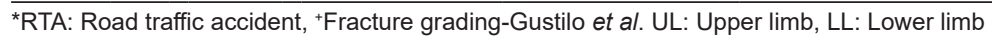

Table 2: Intra operative findings and complications of the flap transfers

\begin{tabular}{|c|c|c|c|c|c|}
\hline $\begin{array}{l}\text { Serial } \\
\text { number }\end{array}$ & Defect & Flaps & Recipient vessels & Complication & $\begin{array}{l}\text { Size of } \\
\text { flaps }(\mathrm{cm})\end{array}$ \\
\hline $1 \mathrm{a}$ & Right forearm avulsion & ALT [Figure 1d and e] & Radial vessel and superficial vein & Nil & $10 \times 22$ \\
\hline $1 b$ & Left foot medial skin loss & Rectus [Figure 1f] femoris & Posterior tibial and venae comitantes & Nil & $7 \times 20$ \\
\hline $2 a$ & Left heel, sole avulsion & ALT & Posterior tibial and venae comitantes & Nil & $10 \times 18$ \\
\hline $2 b$ & Lower third fracture right leg & Rectus femoris & Posterior tibial and venae comitantes & Partial graft loss & $6 \times 15$ \\
\hline $3 a$ & Crush injury right foot & Rectus femoris & Anterior tibial and venae comitantes & Partial graft loss & $7 \times 16$ \\
\hline $3 b$ & Crush injury left foot & ALT [Figure 2b] & Anterior tibial and venae comitantes & Partial graft loss & $15 \times 12$ \\
\hline $4 a$ & Avulsion dorsum of left hand & ALT & Radial vessel and superficial vein & Nil & $7 \times 26$ \\
\hline $4 b$ & Crush injury left foot & Rectus femoris & Posterior tibial and venae comitantes & Nil & $5 \times 16$ \\
\hline $5 a$ & $\begin{array}{l}\text { Grade IIIB fracture middle third left } \\
\text { leg, crush injury foot and anke }\end{array}$ & ALT [Figure 3f] & Anterior tibial and venae comitantes & Nil & $12 \times 29$ \\
\hline $5 \mathrm{~b}$ & Avulsion dorsum of the right foot & Rectus femoris [Figure $3 g$ ] & Posterior tibial and venae comitantes & Nil & $7 \times 22$ \\
\hline
\end{tabular}




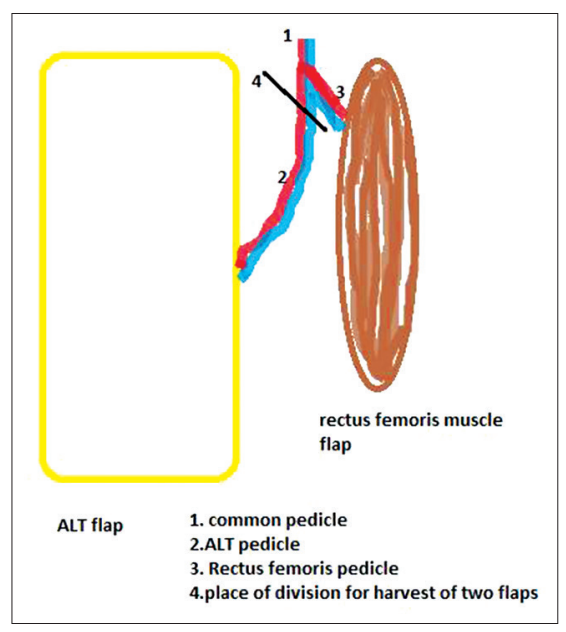

Figure 4: Diagrammatic representation of site of division of anterolateral thigh pedicle. Common pedicle included with rectus pedicle

Table 3: Results of donor area morbidity tests

\begin{tabular}{lccl}
$\begin{array}{l}\text { Patient } \\
\text { number }\end{array}$ & $\begin{array}{c}\text { Strength of } \\
\text { quadriceps } \\
\text { donor thigh }(\mathbf{k g})\end{array}$ & $\begin{array}{c}\text { Strength of } \\
\text { quadriceps } \\
\text { opposite thigh }(\mathbf{k g})\end{array}$ & $\begin{array}{l}\text { Extensor } \\
\text { lag at } \\
\text { donor knee }\end{array}$ \\
\hline 1 & 16 & 17 & None \\
2 & 19 & 20 & None \\
3 & 18 & 18 & None \\
\hline
\end{tabular}

Harvest of two radial forearm flaps from single donor forearm was described by Safak et al.; a total of 16 flaps were harvested from 8 donor areas for oral cavity defects following release of submucous fibrosis over a period of 3 years by this group. ${ }^{[16]}$ Chung Kan Tsao et al. published the harvest of two small ALT flaps for similar defects from one thigh. ${ }^{[17]}$ Bilateral double free flaps were harvested from two thighs for coverage of huge chest wall defect by Gazyakan et al.; they harvested one ALT and one tensor fasciae latae (TFL) from each thigh. ${ }^{[18]}$ In recent times, the lateral circumflex femoral system has been in the forefront allowing ingenous harvesting of skin, muscle and bone relatively independent of each other. $^{[19]}$

An unpublished cadaveric study done in our department showed the feasibility of transferring rectus femoris and ALT flap together on one pedicle. Ten limbs were studied in fresh unpreserved cadavers; the average length of common pedicle was $2.2 \mathrm{~cm}$, ALT pedicle was $6.9 \mathrm{~cm}$, length of rectus pedicle was $2.9 \mathrm{~cm}$. Although this study was done to reveal feasibility of transferring on one pedicle, with this background we choose to use ALT and rectus femoris muscle from the same donor thigh to resurface two different defects.

\section{RESULTS}

All five patients had a planned transfer of the ALT flap and rectus femoris flap to their twin defects [Table 2]. The average pedicle length of ALT flap was $7.1 \mathrm{~cm}$ and of rectus, flap was $2.8 \mathrm{~cm}$, common pedicle was $2.5 \mathrm{~cm}$. Four of the ALT flaps had musculocutaneous perforators, and 1 had a septocutaneous perforator. All donor areas were grafted. We could cover a defect as big as $7 \mathrm{~cm} \times 22 \mathrm{~cm}$ with rectus femoris muscle flap [Figure 3g].

There were no reexplorations; all flaps survived completely. Two patients had partial graft loss over the rectus femoris flap, which was managed conservatively with regular dressings. There were no graft losses in the donor thighs, and there were no infections.

Three of the patients were available for assessment of donor knee function at a mean of 28 months after the procedure. Isometric quadriceps strength was tested for these patients with a dynamometer, with the patient in sitting position and knee at $90^{\circ}$. There was no significant difference in the quadriceps strength as shown in Table 3. None of the patients had an extensor lag at the knee, as shown in Figure 3i.

\section{DISCUSSION}

Tertiary referral centres catering to a large volume of trauma can be faced with the possibility of having to provide flap cover for more than one limb defect. Free tissue transfer is the first and best option in many of these defects on account of the size of the defect and severity of the injury. ${ }^{[14]}$ In multiple defects requiring soft tissue cover, the procedure can be done simultaneously or sequentially, the use of multiple donor sites for a simultaneous reconstruction can add to the operative time, and this can have an adverse effect on the patient's wellbeing. ${ }^{[15]}$ This will also increase the number of raw areas in a polytrauma patient increasing the post-operative pain and morbidity. In an attempt to expedite simultaneous reconstruction within a reasonable time duration and also limiting the number of donor areas, we have adopted a method of harvesting two flaps from the same donor site. The lateral circumflex femoral system has been described as a very versatile system ${ }^{[15]}$ for multiple flap harvest; the availability of large skin paddle in ALT, ${ }^{[20,21]}$ makes it the flap of choice. 
We chose this option of harvesting ALT and rectus femoris muscle for transfer simultaneously instead of two small ALT flaps ${ }^{[17]}$ because the tissue requirement is large in one of the defects. Two ALT flaps from the same thigh would not have sufficed in this situation. ALT and one TFL was not chosen because of the technical difficulties in the design of these flaps in our cases, as the pedicles are close to each other, and again the tissue requirements did not permit us to do so. One ALT and one anteromedial thigh (AMT) flap from the same thigh was not selected because the vascular supply of AMT flap is not always constant. In a study done by Yu and Selber et al. on AMT flaps, the perforator was absent in 21 cases out of hundred; ${ }^{[22]}$ the vessel dissection of AMT is tedious compared to rectus femoris muscle flap, and the vascular anatomy is not very constant. ALT with vastus lateralis flap was not used because this muscle is attached in its whole length to the linea aspera, making the dissection more difficult and time-consuming than rectus femoris. ALT with gracilis from same thigh was not used because it would require a separate incision and dissection, leaving an island of skin in between and an extra donor site scar and also skin graft harvest from the same thigh would be more difficult. ALT from one thigh and gracilis from another thigh was not used because it would increase the operating time and number of donor areas. The dissection of the rectus femoris is relatively easy on account of it having a tendinous origin and insertion and not having much bony attachments in between. The circumflex scapular system is another versatile system that can be used for multiple flap harvest in the form of thoracodorsal artery perforator flap and latissimus dorsi (LD) muscle flap, as is recently published by Jain et al.; ${ }^{[23]}$ but it requires changing the position of patient and also precludes a two team approach. ${ }^{[24]}$ It also increases the operating time. Harvesting ALT and rectus femoris muscle would safely and easily complete the entire procedure with the patient in supine position throughout. Another advantage to the patient is better post-operative analgesia with lumbar epidural when thigh is used as donor area.

Ever since described, the ALT flap has become the workhorse for resurfacing soft tissue defects. With increasing clinical application, the flap has undergone various modifications in terms of design ${ }^{[21]}$ and it has been used as a composite flap along with vastus lateralis, rectus femoris and tensor fascia lata. ${ }^{[14,20]}$ Rectus femoris is another versatile ${ }^{[4]}$ muscle flap, has many applications, with a reliable pedicle and minimal donor site morbidity. ${ }^{[25,26]}$ In this study, there were no shortcomings in the form of inadequate flap size or length of pedicle due to meticulous pre- and intra-operative planning. A careful dissection is needed to preserve the motor nerve branch to the vastus lateralis muscle.

Clinically, in this study, the donor site morbidity was minimal and did not preclude the patients from their daily activities. Quadriceps strength assessment at the donor knee was done with a dynamometer, which showed either no difference with opposite knee or only negligible difference. The only drawback of this study is that gait analysis was not done because all of them had severe foot or leg injury and involving both lower limbs in three cases. None of these patients had any complaints related to donor site [Figure 3j]. A combined harvest of vastus lateralis free flap with ALT was described by Wong et al. ${ }^{\left[{ }^{[9]}\right.}$ and Posch et al. ${ }^{[27]}$ with minimal donor site morbidity. We described ALT and rectus femoris, as the dissection of the latter is less tedious and less time consuming than vastus lateralis.

In a study comparing LD and ALT donor site morbidity by Horn et al., morbidity was slightly higher in the LD group (7\%) compared to ALT group (5\%). In all our cases, ALT flap was raised preserving iliotibial tract and we meticulously repaired the vastus lateralis muscle and the muscle defect was closed by properly approximating the free edge of vastus medialis tendon to the free edge of the vastus lateralis tendon and reefing the stump of rectus femoris tendon to the quadriceps tendon. This would avoid post-operative weakness of knee extension as suggested by Wei et al. ${ }^{[5]}$ None of our patients complained of any deficit in knee function. Because of the above two reasons, we believe donor site morbidity in our cases is minimal or absent. Muscle flaps may appear aesthetically poor initially [Figure $2 \mathrm{~b}$ ], but they subsequently undergo atrophy [Figure $2 c$ ] and can be safely debulked if need be, as suggested in a study by Chowdary and Murphy|28] and also experience in our institution suggests the same.

\section{CONCLUSION}

Simultaneous harvest of ALT and rectus femoris is a viable and safe option to resurface two different post-traumatic limb defects. Meticulous dissection at the pedicle site is important to avoid injury to vastus lateralis motor branch. Proper planning is important to avoid problems such as inadequate pedicle length and flap size. Major 
advantages of choosing thigh over back is a reduction in operating time, simultaneous two team approach and better post-operative pain management. Careful reefing of rectus femoris tendon stump to the quadriceps tendon after harvest is required to minimise donor-site morbidity. In experienced hands, complications are minimal postoperatively. Hence, we suggest this option for trauma patients with two different defects requiring soft tissue coverage.

\section{Acknowledgement}

The authors would like to thank R. Srikanth, Professor and Head of the Department, Department of Plastic Surgery, Nizam's Institute of Medical Sciences, Hyderabad, Telangana, India for his invaluable input towards final draft preparation.

\section{Financial support and sponsorship}

Nil.

\section{Conflicts of interest}

There are no conflicts of interest.

\section{REFERENCES}

1. Song YG, Chen GZ, Song YL. The free thigh flap: A new free flap concept based on the septocutaneous artery. $\mathrm{Br} \mathrm{J}$ Plast Surg 1984;37:149-59.

2. Tsuji N, Suga H, Uda K, Sugawara Y. Functional evaluation of anterolateral thigh flap donor sites: Isokinetic torque comparisons for knee function. Microsurgery 2008;28:233-7.

3. Townley WA, Royston EC, Karmiris N, Crick A, Dunn RL. Critical assessment of the anterolateral thigh flap donor site. J Plast Reconstr Aesthet Surg 2011;64:1621-6.

4. Daigeler A, Fansa H, Altmann S, Awiszus F, Schneider W. The pedicled rectus femoris muscle flap for reconstruction of complicated abdominal wall defects. Rozhl Chir 2005;84:238-43.

5. Wei CY, Chuang DC, Chen HC, Lin CH, Wong SS, Wei FC. The versatility of free rectus femoris muscle flap: An alternative flap. Microsurgery 1995;16:698-703.

6. Koshima I, Moriguchi T, Inagawa K, Urushibara K. Dynamic reconstruction of the abdominal wall using a reinnervated free rectus femoris muscle transfer. Ann Plast Surg 1999;43:199-203.

7. Koshima I, Moriguchi T, Soeda S, Hamanaka T, Tanaka H, Ohta S. Free rectus femoris muscle transfer for one-stage reconstruction of established facial paralysis. Plast Reconstr Surg 1994;94:421-30.

8. Arai T, Ikuta Y, Ikeda A. A study of the arterial supply in the human rectus femoris muscle. Plast Reconstr Surg 1993;92:43-8.

9. Wong $\mathrm{CH}$, Ong YS, Wei FC. The anterolateral thigh - Vastus lateralis conjoint flap for complex defects of the lower limb. J Plast Reconstr Aesthet Surg 2012;65:235-9.

10. Tsao CK, Wei FC, Chang YM, Cheng MH, Chwei-Chin Chuang D, Kao HK, et al. Reconstruction of the buccal mucosa following release for submucous fibrosis using two radial forearm flaps from a single donor site. J Plast Reconstr Aesthet Surg 2010;63:1117-23.

11. Samir K, Shrirang P, Anurag C. Double flap from amputated opposite lower limb for cover of plantar and dorsal surfaces of a crushed foot. Indian J Plast Surg 2013;46:568-71.

12. Tamai S, Komatsu S, Sakamoto H, Sano S, Sasauchi N. Free muscle transplants in dogs, with microsurgical neurovascular anastomoses. Plast Reconstr Surg 1970;46:219-25.

13. Schenck RR. Free muscle and composite skin transplantation by microneurovascular anastomoses. Orthop Clin North Am 1977;8:367-75.

14. Chen HC, El-Gammal TA, Chen HH, Wei FC, Lin CH, Tang YB. Economy of donor site incisions: Multiple free flaps of the subscapular family for extensive extremity wounds and bilateral foot defects. Ann Plast Surg 1998;41:28-35.

15. Lin $\mathrm{CH}$, Wei FC, Lin YT, Yeh JT, Rodriguez Ede J, Chen CT. Lateral circumflex femoral artery system: Warehouse for functional composite free-tissue reconstruction of the lower leg. J Trauma 2006;60:1032-6.

16. Safak T, Akyürek M. Creating two independent fasciocutaneous free flaps from a single radial forearm donor site. Ann Plast Surg 2001;47:247-51.

17. Huang JJ, Wallace C, Lin JY, Tsao CK, Kao HK, Huang WC, et al. Two small flaps from one anterolateral thigh donor site for bilateral buccal mucosa reconstruction after release of submucous fibrosis and/or contracture. J Plast Reconstr Aesthet Surg 2010;63:440-5.

18. Gazyakan E, Engel H, Lehnhardt M, Pelzer M. Bilateral double free-flaps for reconstruction of extensive chest wall defect. Ann Thorac Surg 2012;93:1289-91.

19. Acartürk TO. Femur-vastus intermedius-anterolateral thigh osteomyocutaneous composite chimeric free flap: A new free flap for the reconstruction of complex wounds. J Reconstr Microsurg 2011;27:187-94

20. Wei FC, Jain V, Celik N, Chen HC, Chuang DC, Lin CH. Have we found an ideal soft-tissue flap? An experience with 672 anterolateral thigh flaps. Plast Reconstr Surg 2002;109:2219-26.

21. Ahmad QG, Yadav PS, Shankhdhar VK, Nambi GI. Anterolateral thigh twin free flaps from a single donor site-a modification based on the oblique branch of the lateral circumflex femoral artery. Indian J Surg 2014;76:165-8.

22. Yu P, Selber J. Perforator patterns of the anteromedial thigh flap. Plast Reconstr Surg 2011;128:151e-7e.

23. Jain $L$, Kumta $S$, Purohit $S$. One on one free: Two free flaps from a single donor site. J Plast Reconstr Aesthet Surg 2015;68:140-2.

24. Horn D, Jonas R, Engel M, Freier K, Hoffmann J, Freudlsperger C. A comparison of free anterolateral thigh and latissimus dorsi flaps in soft tissue reconstruction of extensive defects in the head and neck region. J Craniomaxillofac Surg 2014;42:1551-6.

25. Gardetto A, Raschner CH, Schoeller $\mathrm{T}$, Pavelka $\mathrm{ML}$, Wechselberger G. Rectus femoris muscle flap donor-site morbidity. Br J Plast Surg 2005;58:175-82.

26. Sbitany H, Koltz PF, Girotto JA, Vega SJ, Langstein HN. Assessment of donor-site morbidity following rectus femoris harvest for infrainguinal reconstruction. Plast Reconstr Surg 2010;126:933-40.

27. Posch S, Mureau MA, Flood SJ, Hofer SO. A combined free partial vastus lateralis with anterolateral thigh perforator flap reconstruction in extensive composite defects. Br J Plast Surg 2005;58:1095-103.

28. Chowdary RP, Murphy RX. Delayed debulking of free muscle flaps for aesthetic contouring debulking of free muscle flaps. $\mathrm{Br} J$ Plast Surg 1992;45:38-41. 